\title{
BMJ Open Implementation of the Moyo fetal heart rate monitor in district hospitals in Bihar, India: a feasibility study
}

\author{
Hanna Oommen (D) , ${ }^{1,2}$ Kunal Ranjan, ${ }^{3}$ Sudha Murugesan, ${ }^{3}$ Aboli Gore, ${ }^{3}$ \\ Sunil Sonthalia, ${ }^{3}$ Pradeep Ninan, ${ }^{4}$ Stine Bernitz, ${ }^{5}$ Ingvil Sorbye, ${ }^{6}$ Mirjam Lukasse ${ }^{5,7}$
}

To cite: 0 ommen $\mathrm{H}$,

Ranjan K, Murugesan S, et al. Implementation of the Moyo fetal heart rate monitor in district hospitals in Bihar, India: a feasibility study. BMJ Open 2021;11:e041071. doi:10.1136/ bmjopen-2020-041071

- Prepublication history and additional material for this paper is available online. To view these files, please visit the journal online (http://dx.doi.org/10. 1136/bmjopen-2020-041071)

Received 03 June 2020 Revised 12 January 2021 Accepted 18 January 2021

Check for updates

(C) Author(s) (or their employer(s)) 2021. Re-use permitted under CC BY-NC. No commercial re-use. See rights and permissions. Published by BMJ.

For numbered affiliations see end of article.

Correspondence to

Dr Mirjam Lukasse;

Mirjam.Lukasse@usn.no

\section{ABSTRACT}

Objectives Globally, half of all stillbirths occur during birth. Detection of fetal distress with fetal heart rate monitoring (FHRM), followed by appropriate and timely management, might reduce fresh stillbirths and neonatal morbidity. This study aimed to investigate the barriers and facilitators for the implementation of Moyo FHRM use in Bihar state, and secondarily, the feasibility of collecting reliable obstetrical and neonatal outcome data to assess the effect of implementation.

Setting CARE Bihar and the hospital management at four district hospitals (DHs) in Bihar state, each with 6500 to 15 000 deliveries a year, agreed to testing the implementation of Moyo FHRM through a process of meetings, training sessions and collecting data. At each hospital, a clinical training expert was trained to train others, while a clinical assessment facilitator collected data.

Methodology Observational notes were taken at all training sessions and meetings. Individual interviews $(n=4)$ were conducted with clinical training experts (CTEs) on training experiences and barriers and facilitators for Moyo FHRM implementation. The CTEs recoded field notes in diaries. Descriptive analyses performed on preimplementation and post-implementation data $(n=521)$ assessed quality and completeness.

Results Main barriers to implementation of Moyo FHRM were health system and cultural challenges involving (1) existing practices, (2) insufficient human resources, (3) action delays and (4) cultural and local challenges. Another barrier was insufficient involvement of doctors. Facilitators for implementation were easy use of the Moyo FHRM device and adequate training for staff.

Electronic collection of obstetrical data worked well but had substantial missing data.

Conclusion Health system and cultural challenges are a major constraint to Moyo FHRM implementation in low-resource settings. Improvements at all levels of infrastructure, practices and skills will be critical in busy DHs in Bihar. Full-scale implementation needs doctor-led leadership and ownership. Obstetrical data collection for the purpose of scientific analysis needs to be improved.

\section{BACKGROUND}

Each year, globally, 2.7 million babies die during the first 28 days of life, 2.6 million are stillborn and 1 million of surviving infants develop neurocognitive problems due to

\section{Strengths and limitations of this study}

- To our knowledge, this is the first study to explore the implementation of Moyo fetal heart rate monitor in India.

- Qualitative and quantitative design were used, which provides a more complete picture of the implementation process in a complex environment.

- The study also considered social norms through early engagement with local staff in the district hospitals and using the existing health infrastructure as well as considering cultural and environmental influences.

- Quantitative data was collected only during daytime and may not give the whole picture of the situation. The quantitative data had substantial missing data.

- Since the number of quantitative data participants and the use of the Moyo devices was low, the study does not allow for reliable interpretation of the preimplementation and post-implementation data due to insufficient power.

birth asphyxia. $^{1-3}$ To reduce the number of fresh stillbirths, neonatal deaths and infant disability, it is necessary to improve the quality of care by appropriate use of effective clinical and non-clinical interventions, strengthening of health infrastructure and development of optimum skills and a positive attitude among health providers. ${ }^{45}$ Adequate fetal heart rate monitoring (FHRM) during labour is an intervention that has reduced intrapartum asphyxia in high-income countries, ${ }^{67}$ but little is known about monitoring practices in low-resource settings. WHO and International Federation of Gynecology and Obstetrics (FIGO) guidelines recommend FHRM during labour every 15 to 30 min during first stage, every 5 min during second stage, monitored on a periodic basis depending on the low-risk or high-risk pregnancy. ${ }^{67}$ If the fetal heartrate (FHR) is abnormal, it indicates fetal distress and procedures for emergency obstetrical care. ${ }^{6} 7$ FHRM requires adequate staff, resources, skills and equipment in the 
obstetric facility. Detected fetal distress on the other hand must trigger appropriate and timely obstetrical responses like (1) discontinuation of oxytocin, ${ }^{8}$ (2) putting the mother in left lateral position, (3) consider giving oxygen, (4) ensure the mother is well-hydrated and give intravenous fluids if necessary or (5) plan for immediate delivery, often by caesarean section (CS). ${ }^{9}$

In high-income countries, FHRM during labour is most commonly accomplished using fetal cardiotocography (CTG), which registers contractions and fetal heart rate simultaneously. ${ }^{6}$ However, there are disadvantages related to CTG use in low- and middle-income countries: (1) it is expensive, (2) the interpretation of the output/results requires advanced skills and knowledge while poor ability to interpret monitoring output may result in unnecessary caesarean deliveries ${ }^{9}$ and (3) the device requires maintenance, in particular when exposed to fine dust. An alternative to electronic fetal monitoring using CTG has been intermittent auscultation using a Pinard or handheld Doppler. Recently, Laerdal Global Health developed the Moyo FHRM, a low cost, simple-to-use and robust but small digital tool as an alternative to handheld Doppler in a low-cost setting. ${ }^{10}$ Moyo FHRM has several benefits compared with Doppler. First, the possibility for continuous FHRM and a 30-min histogram display button, which is important because the number of cases diagnosed with fetal distress is directly proportional to the intensity of intrapartum monitoring. ${ }^{9}{ }^{11}$ Second, Moyo allows comparison of maternal and fetal heart rates. Third, Moyo has audio-visual alarms if abnormal FHR is detected, following the FIGO guidelines. ${ }^{6}{ }^{10}$ Finally, Moyo has the ability to record the entire monitoring sessions in its memory card for debriefing afterwards. ${ }^{10}$ In a study conducted in Tanzania these improvements led to more frequent and timely obstetrical responses. ${ }^{12}$

The Ministry of Health $(\mathrm{MOH})$ in India published new guidelines in 2018 to standardise and strengthen care quality and quantity in the labour rooms (LR) and operation theatres (OT) particularly of district hospitals (DH) ${ }^{13}$ FHRM during labour is a part of the new recommendations. ${ }^{13}$ In India, the challenges in public hospitals are complex, including deficient infrastructure and inadequate staffing, ${ }^{14}$ absenteeism among health service providers,${ }^{15}$ lack of equipment, inexpedient distribution of hospital beds, inequality of services, unmanageable patient load, rural-urban dichotomy in health services, high out-of-pocket expenditure and low accountability. ${ }^{14}$

Since the highly populated state of Bihar was one of the areas in India with the highest infant mortality rate in $2005,{ }^{16} 17$ the government of Bihar asked CARE India's support to address the health challenges in the state. CARE India launched a multilevel intervention programme 'Bihar Technical Support Program (BTSP)' in $2011 .^{18}$ Our study is one of the facility level interventions piloted in the DHs where CARE has run their programme.

The main objective of this paper was to investigate the barriers and facilitators for the implementation of Moyo
FHRM use in DHs in Bihar, and secondarily, the feasibility of collecting reliable obstetrical and neonatal outcome data to assess the effect of implementing the Moyo FHRM.

\section{METHODOLOGY \\ Study design}

A combination of quantitative and qualitative methods was chosen for the study. ${ }^{19}$ This included individual interviews, observational notes of all meetings and training sessions, a test of skills and knowledge of the clinical training experts (CTEs), diaries kept by the CTEs and quantitative data collection (figure 1). We used an explorative qualitative design to address implementation bottlenecks, identify optimal approaches for the particular setting of DHs in Bihar state. We included a quantitative data collection of obstetrical and neonatal outcomes in order to assess if high quality data can be collected to scientifically assess the effect of a full-scale implementation in the future.

\section{Study setting}

The reproductive health related health indicators show poorer outcomes in Bihar compared with those from India as a whole ${ }^{161720}$ (table 1).

The BTSP facility level interventions in DHs included training in: (1) conducting safe deliveries, (2) routine and essential newborn care practices including Helping Babies Breathe (HBB) programme ${ }^{21}$ and (3) complication management. ${ }^{18}$ Instrumental delivery training for doctors was conducted in 2016-2017. The infant mortality rate significantly decreased from 61 per 1000 live births in 2005 to 38 per 1000 live births in $2018 .^{18}$ Our study was carried out in; Bhojpur, Katihar, Siwan and Purba Champaran. Three of the DHs had existing guidelines recommending FHRM every 30 min during labour. All the DHs had two Doppler monitors available, none of them had CTGs or Pinards in use. The DHs are called A, B, C and D for purposes of anonymity and confidentiality. The DHs' labour characteristics and obstetric departments' staff are presented in the table 2 .

\section{Programme design for the Moyo FHRM implementation process}

The research team contacted CARE Bihar, who in turn suggested four DHs and on the agreement of the managers of these hospitals established the management team. The implementation plan and the data collection tool were discussed and finalised by the management team. The adaption of the existing method of data collection included the introduction of 10 new variables. Four CTEs working in the districts before the study, were chosen to coordinate the implementation process in their own DHs and train the staff. The CTEs were trained by the first author in May 2018 (figure 1). The focus of the training was; how to use Moyo FHRM and facilitate and conduct training sessions in Hindi for the local staff. Laerdal Global Health's training material ${ }^{10}$ was used and 


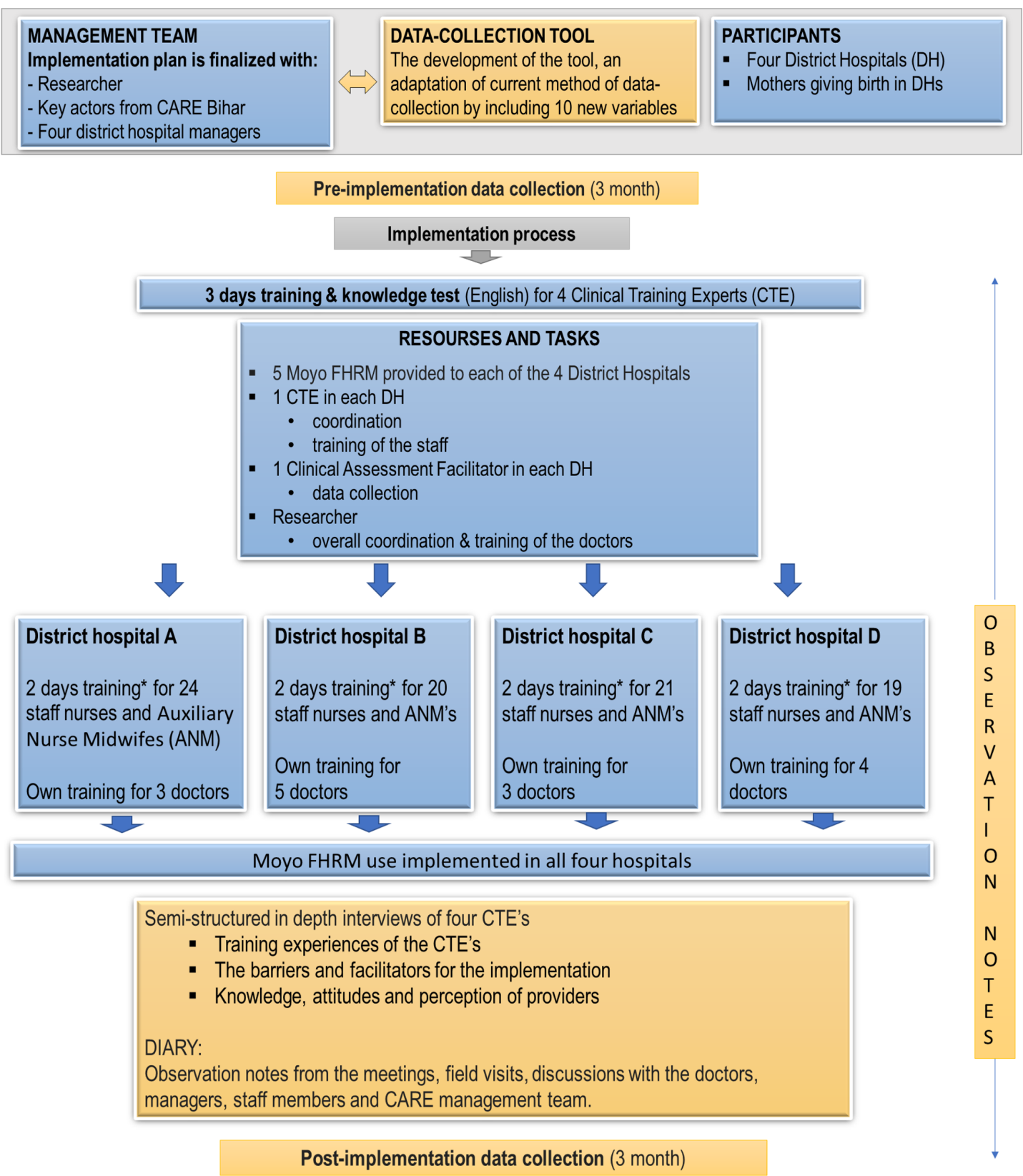

*Training (hindi) included theoretical and practical part. Laerdal Global Health had produced the training materials (flip-chart, question cards, role games)

Implementation process

Data collection

Figure 1 Flow chart of the implementation and data collection process. ${ }^{*}$ Training (Hindi) included theoretical and practical part. Laerdal Global Health had produced the training materials (flip chart, question cards, role games). Implementation process.

Data collection. FHRM,fetal heart rate monitors.

hands-on training conducted in the DH. The four CTEs completed an individual knowledge test at the end of the training, assessing their capacity to pass on the new knowledge. The test, constructed by the first author included questions from Laerdal Global Health's training cards.

Once the CTEs had trained most of the staff, Moyo FHRM was taken in use in all the DHs in November 2018. CTEs provided monthly additional supervision. The first author had regular contact with the CTEs to resolve any challenges in the field as soon as possible. In total 84 labour room staff nurses/auxiliary nurse midwives (ANMs) in four DHs were trained to use Moyo FHRM during 2 days of training sessions and $68 \%(n=57)$ participated in refreshment sessions. The age range of staff was 23 to 55 years and the median years of experience in labour care was 6 years. In total 15 doctors from the four DHs were able to participate in a 1 to 2 hours training. 
Table 1 Reproductive health indicators in India and Bihar 2015-2016

\begin{tabular}{|c|c|c|}
\hline & India & Bihar state \\
\hline Total population in 2016 & 1309000000 & 103804637 \\
\hline Literacy rate* & $74.4 \%$ & $61.8 \%$ \\
\hline Age of mother at first birth & 19.9 & 17.5 \\
\hline Total fertility rate & 2.4 & 3.4 \\
\hline Skilled attendant at birth $\dagger$ & $81.4 \%$ & $70 \%$ \\
\hline Institutional delivery & $78.9 \%$ & $63.8 \%$ \\
\hline Population caesarean section & $17.2 \%$ & $6.2 \%$ \\
\hline Institutional caesarean section $\ddagger$ & $21.8 \%$ & $9.7 \%$ \\
\hline Stillbirth rate & 23/1000 births & $54 / 1000$ births \\
\hline Neonatal mortality rate (first 28 days) & 26.4/1000 live births & 26 to $30 / 1000$ live births \\
\hline Maternal mortality rate & $174 / 100000$ live births & - \\
\hline
\end{tabular}

*Year 2011.

†A skilled birth attendant is an accredited health professional-such as a midwife, doctor or nurse.

łInclude district hospitals, referral hospitals and private hospitals.

\section{Participants and data collection}

Data collection started in May 2018 with observational notes of all meetings and training sessions with the CTEs by the researcher (first author). All involved were informed, and consented to the data collection. After training of the staff by CTEs and implementation of Moyo FHRM in the DHs, the four CTEs were interviewed individually using an interview guide (online supplemental file 1: Interview guide and diary instructions). The four CTEs purposely selected, based on their competence as senior nurse-midwives with extensive clinical and teaching experience. Each of them had been coordinating facility-level interventions in the districts from 2012. The interview guide was developed to gain information on (1) the challenges experienced by the CTEs, (2) observations they had made about the staff's knowledge, attitude and perception of the of the Moyo device use and (3) completion of the training. The interviews lasted approximately 1 hour each, were conducted in English and audio-recorded.

Table 2 Labour characteristics and obstetric departments' staffing in the four DHs year 2017 (12 months prior to the Moyo FHRM implementation)

\begin{tabular}{|c|c|c|c|c|}
\hline Perinatal health variables & Hospital A & Hospital B & Hospital C & Hospital D \\
\hline Deliveries/year & 6500 & 15000 & 8078 & 11045 \\
\hline Stillbirths/year n (\%) & $130(2 \%)$ & $400(2.7 \%)$ & $153(1.9 \%)$ & $210(1.9 \%)$ \\
\hline Fresh stillbirths/year n (\%) & - & - & $130(1.6 \%)$ & $74(0.7 \%)$ \\
\hline $\begin{array}{l}\text { Caesarean section/year n (\%) } \\
\text { Operative vaginal rate }\end{array}$ & $\begin{array}{l}114(1.8 \%) \\
0\end{array}$ & $\begin{array}{l}1180(7.9 \%) \\
0\end{array}$ & $\begin{array}{l}782(9.7 \%) \\
0\end{array}$ & $\begin{array}{l}782(9.68 \%) \\
0\end{array}$ \\
\hline Newborn stimulation* & $232(3.6 \%)$ & $284(1.9 \%)$ & $558(6.9 \%)$ & $1137(10.3 \%)$ \\
\hline Premature, $<37$ gestational week $\dagger$ & $34(0.5 \%)$ & $170(1.1 \%)$ & $180(2.2 \%)$ & - \\
\hline \multicolumn{5}{|l|}{ Human resources } \\
\hline Staff nurse/ANM per shift $\ddagger$ & 5 & 3 & 4 & 4 \\
\hline RN/RM night shift & 3 & 3 & 3 & 2 \\
\hline Doctors on call daytime & 2 & 1 & 2 & 1 \\
\hline Doctors on call night-time & 1 & 1 & 1 & 1 \\
\hline \multicolumn{5}{|l|}{ Hospital capacity } \\
\hline Number of maternity beds§ & 35 & 27 & 30 & 30 \\
\hline
\end{tabular}

Data: Information provided by the CTEs.

*Using Helping Babies Breathe (HBB) actions. ${ }^{21}$

†Prematurity definition is challenging because of the low number of antenatal visits and error estimates happen easily.

$\ddagger$ Auxiliary nurse midwife: Village-level female health worker who is the first contact person between the community and the health services.

§In total including labour room, antenatal, postoperative and postnatal wards.

CTEs, clinical training experts; DHs, district hospitals; FHRM, fetal heart rate monitor; RM, registered midwife; RN, registered nurse. 
The observations and field notes by the CTEs during the process were recorded in a diary. CTEs were instructed to actively ask nurses and doctors about their experiences with, and opinions about the Moyo FHRM compared with Doppler, as well as their thoughts about the implementation process. The researcher went through all the field notes with the CTEs to identify challenges, implementation bottlenecks, attitudes, experiences and opinions about the new device compared with Doppler.

Quantitative pre-implementation and postimplementation data collection, by the clinical assessment facilitators (CAFs), trained by CARE Bihar, took place from July to September 2018 and November 2018 to January 2019 (figure 1). CAFs had experience in reproductive health data collection using the electronic data collection tool used during the study. They were only available for data collection during the daytime on weekdays and for 1 week a month at each DH. Inclusion criteria were mothers in active labour (from $4 \mathrm{~cm}$ cervix dilation) and at term as defined by local staff. All the participants were classified as falling into either low-risk or high-risk pregnancy category. High-risk pregnancies included: eclampsia, induced birth, infection, diabetes, anaemia, fetal distress, meconium-stained amniotic fluid, low liquor, breech birth, small for date, immunisation, use of oxytocin, mother with fever and protracted labour. Exclusion criteria were: $<37$ weeks gestation, multiple pregnancy, intrauterine death, admission late in second stage of labour (too late for interventions to be used) and emergency situations requiring immediate action, for example, antepartum haemorrhage. Key outcome measures were (1) Moyo FHRM use in labour, (2) normal/abnormal FHR, (3) newborns cry immediately after birth and (4) need for newborn stimulation (HBB programme) or transfer. Time from detection of abnormal FHR to delivery, number of alarms and obstetrical interventions (oxytocin use, change of position, use of intravenous fluids and oxygen use) were recorded.

\section{Data analysis}

Qualitative data analysis was guided by the principles of conventional content analysis and the coding categories were derived directly from the text data. ${ }^{22}$ The first author coded and analysed each transcript independently. Table 3 illustrates how the transcribed text was condensed into codes and categories. When the coding was finalised, the first author ran queries, read and re-read the coded transcripts to synthesise themes and to identify interesting outliers and surprising features of the data. The first author then summarised findings and questions in briefing notes that were sent and discussed with the last author. Online meetings were held to discuss all parties' impressions of the findings, to validate interpretations of the data and to fill in any gaps in the analysis. The first author kept a diary about the ideas of emerging themes, surprising findings and other details useful for analysing and interpreting the data. To assess feasibility and the quality and quantity of quantitative data collection we performed descriptive analyses, numbers and proportions, using the SPSS programme.

\section{Patient and public involvement}

Patients or the public were not involved in the design, or conduct, or reporting, or dissemination plans of our research.

\section{RESULTS}

Three major themes were identified from the qualitative data about the barriers and facilitators for implementation of Moyo FHRM during labour: (1) health system and cultural challenges, (2) implementation improvement areas and (3) FHRM Moyo device usability. The results are presented in these categories followed by the results of quantitative pre-implementation and postimplementation data.

\section{Health system and cultural challenges}

The health systems and cultural challenges including four main areas: (1) existing practices, (2) insufficient human resources, (3) action delays and (4) other local and cultural challenges (table 4).

The DHs were not following the existing national guide$\operatorname{lines}^{6}$ (table 4). Doctors had previously been trained to conduct instrumental vaginal deliveries, but this skill was not used because of the lack of support during the learning phase (doctors are alone on duty) and high turnover among the doctors.

The lack of human resources was very obvious in three of the hospitals and the staff described feeling overwhelmed by the high workload and unable to adequately monitor each woman in labour. The overwhelming workload affected their attitude:

"Staff think that if they monitor with Moyo they are forced to follow-up. If monitoring is not on, there is no need to follow-up." (CTE 2, Hospital B)

In the post-implementation meetings, CTE nurses described the challenges getting the staff, nurses/ANMs, to use the Moyo for FHRM. Doctors were not insisting that staff use the Moyo. Consequently, staff did not start using it regularly. CTEs also reported that CS for

Table 3 Few examples of the analytical process

\begin{tabular}{lll}
\hline Transcribed text & Code & Category \\
\hline Human resources are one of the biggest problems. & Lack of human resources. & Health system challenges. \\
Documentation, no time to do a good a job. & Poor documentation. & Health system challenges. \\
\hline
\end{tabular}


Table 4 Health system and cultural challenges when implementing Moyo FHRM in four DHs in Bihar

\begin{tabular}{|c|c|c|c|}
\hline Existing practices & Insufficient human resources & Action delays & $\begin{array}{l}\text { Other cultural and local } \\
\text { challenges }\end{array}$ \\
\hline $\begin{array}{l}\text { DHs are not following national } \\
\text { guidelines. } \\
\text { No systematic FHRM during labour. } \\
\text { CS not done due to fetal reasons. } \\
\text { Partogram not used (documentation). } \\
\text { Instrumental deliveries not common. }\end{array}$ & $\begin{array}{l}\text { High workload. } \\
\text { Unable to adequately monitor } \\
\text { each woman in labour. } \\
\text { Only one doctor on call with } \\
\text { multiple tasks. }\end{array}$ & $\begin{array}{l}\text { Need to wait for gynaecologist or } \\
\text { anaesthesiologist. } \\
\text { Concurrency conflict. } \\
\text { Challenges with the other teams } \\
\text { (laboratory staff, operation team). } \\
\text { Delay in obtaining consent to } \\
\text { operate from the relatives. } \\
\text { Lack of needed laboratory tests. }\end{array}$ & $\begin{array}{l}\text { High turnover among the } \\
\text { doctors leads to constant need } \\
\text { for skill training. } \\
\text { Hospital hierarchy. } \\
\text { Patient's and relative's attitude } \\
\text { towards female babies. }{ }^{*} \\
\text { Possibility to buy oxytocin } \\
\text { without prescription. } \\
\text { Oxytocin use without ordination. } \\
\text { The fear of losing the new Moyo } \\
\text { FHRM devices. }\end{array}$ \\
\hline
\end{tabular}

*The healthcare providers always need consent from the family if there is a need for caesarean section. The family's attitude towards female babies could affect the response time.

CS, caesarean section; DHs, district hospitals; FHRM, fetal heart rate monitor.

neonatal reasons (diagnosis of birth asphyxia) had not been performed before the implementation. During the post-implementation phase, they mentioned a few cases where CS was performed for neonatal reasons after the alarms. The cases were not included in the quantitative data collection due to data collection timing. Delays were common in the DHs, from the time the CS decision was made to the actual surgery, and varied from $20 \mathrm{~min}$ to 3 hours. The reasons were many (table 4 ), and the following comment is an example that illuminates one of them:

"I came to a situation, where a family was not ready for CS even when told that we are compromising the mother's and baby's health if we do not do anything. Then after 2 hours we get permission. Then we hear that anaesthesiologist is not available and we need to send the mother to another hospital." (CTE 3, Hospital C)

Other local and cultural challenges were the community members' attitude towards female babies. This affected the parent's decision-making process when the condition of the baby required action during labour or right after birth: They did not always demand or wish the same interventions if they were expecting a female baby as they would if expecting a male baby.
"In a country that is male dominant, the female baby's life does not matter so much." (CTE 2, Hospital B)

Another challenge described by staff and CTEs were the situations where unnecessary oxytocin was given to the mothers against extra payment in hope that the mother would deliver faster. Oxytocin use was not followed by FHRM.

All the CTEs mentioned the fear of losing the new Moyo FHRM devices:

"Nurses fear that if the continuous monitor is on mothers during the first phase when they are active, they may not return it. Now we use the monitor only for those patients who are inside the facilities. For the nurse on duty it is difficult to follow all the patients as to where they are and what they are doing." (CTE 4, Hospital D)

"There is also a risk that medical and nursing students may find the monitors interesting and take them from the labour room." (CTE 1, Hospital A)

\section{Implementation improvement areas}

Areas needing improvement in DHs when implementing Moyo FHRM are listed in table 5.

Most of the staff nurses/ANMs were highly motivated to learn and participate in the training, but it was not easy

Table 5 Areas needing improvement when implementing Moyo FHRM in four DHs in Bihar

\begin{tabular}{|c|c|c|c|}
\hline Health system & Management & Training of staff & Support network \\
\hline $\begin{array}{l}\text { Improving the existing } \\
\text { practices according to } \\
\text { national guidelines. } \\
\text { Finding ways to keep } \\
\text { equipment in safe places. }\end{array}$ & $\begin{array}{l}\text { Making the staff aware of the } \\
\text { existing national guidelines. } \\
\text { Making sure that the staff is } \\
\text { able to follow the guidelines. } \\
\text { Doctors need to lead the } \\
\text { implementation process in DHs. } \\
\text { Reconciling the tasks and } \\
\text { workload of staff. }\end{array}$ & $\begin{array}{l}\text { Sufficient uninterrupted } \\
\text { training time for staff. } \\
\text { Own training programme for } \\
\text { doctors. } \\
\text { Regular case review sessions. }\end{array}$ & $\begin{array}{l}\text { A support network for doctors } \\
\text { where they can get support } \\
\text { during the decision-making } \\
\text { process, especially during } \\
\text { learning phase. }\end{array}$ \\
\hline
\end{tabular}


to organise a common training session. Large workload and limited number of human resources (HR) caused challenges:

"Sometimes the department workload was so much that the nurses had to leave the training between the sessions. That was irritating for the nurses, not to be able to focus $100 \%$. Tired nurses because of the workload. Nurses like to learn new things, and that is why they were happy to come to the training." (CTE 4, Hospital D)

Many doctors faced the same obstacles to participate or concentrate on the training, because of lack of HR or other responsibilities at the same time. A training focussing on the interpretation of normal, suspicious and pathological FHR findings through several cases as well as actions needed to be taken in these situations was found to be very useful. Some doctors expressed the desire for regular casework. Several doctors mentioned, when discussing previous instrumental delivery training, that many of those who had participated in the training were no longer working in the labour wards. There is a high turnover rate among doctors in the DHs.

"Birth asphyxia is the cause of neonatal mortality in $50 \%$ of the cases in Bihar. Some doctors use CTG in private clinics, and have understanding about FHRM, but here the biggest concern is the workload.

Doctors often change jobs." (CTE 1, Hospital A)

The duration of training for staff nurse/ANMs was appropriate and the different learning tools supported learning and activated participation. The practical part of the training in the labour room was considered important.

\section{FHRM Moyo device usability compared with Doppler}

The clinical staff perceived the Moyo device as a useful tool compared with the Doppler. Moyo was perceived as easy to learn how to use, and appropriate for their setting. A detailed list over the benefits mentioned by staff to the CTEs with Moyo FHRM versus Doppler is presented in online supplemental table 1).

\section{Quantitative pre-implementation and post-implementation data and functionality of the data collection plan}

In four DHs, where Moyo FHRM was implemented, data from 515 deliveries were directly observed during the preimplementation $(\mathrm{n}=265)$ and post-implementation period $(n=256)$. Data collection revealed substantial missing data for obstetrical background (online supplemental table 2) and outcomes (online supplemental table 3). Data was collected for all women the CAFs considered potential candidates for the use of Moyo FHRM. Only 36\% ( $n=98$ ) of the mothers in first or second stage of labour received care using the Moyo. Among these, 98\% were implemented by the nurses/ANMs. The device was used for less than 5 min in almost $72 \%$ of the cases. In $24 \%$ of the cases the device was used continuously, while $4 \%$ had it for 5 to $10 \mathrm{~min}$. Personnel who mostly interpreted the Moyo output were nurses/ANMs (97\%). The device generated a total 13 alarms among nine women. Major reason behind all these 13 alarms were 'due to detachment', and the action taken to manage the case was 'maternal position change'. Cases were diagnosed within $4 \mathrm{~min}$ post alarm. In one case was the mother's pulse mistaken for the fetal heart rate. Post-implementation uptake of use of Moyo FHRM was too low to allow reliable impact measure estimations. (online supplemental table 3).

More than one-third of all pregnant women were admitted during the second stage of labour $(10 \mathrm{~cm}$ cervix dilatation on first examination) (online supplemental table 3). Data collection did not capture time from admission to birth. Data collection showed that some variables and categories gave rise to misunderstanding and possible wrong registration. Length of pregnancy was recorded in gestational weeks of pregnancy while staff and women mostly use the terms 'preterm' and 'term'.

\section{DISCUSSION}

The main findings in this feasibility study from a lowresource setting demonstrate barriers to the implementation of a fetal heart rate monitoring system during labour including existing medical practices, lack of human resources, action delays and other cultural and local challenges. Specific areas to improve implementation were identified. In contrast, usability of the Moyo FHRM device and adequate training for staff nurses/ANMs were facilitators for implementation. The Moyo was used far less than anticipated. Quantitative data collection had substantial missing data and some classification challenges.

\section{Contextual feasibility}

The study results clearly illustrate why a feasibility study is important and a closer look at the implementation process is necessary when introducing a FHRM. Although the intervention design and processes may be the same in different countries, the culture of each place is different creating unique barriers and facilitators. Our results support researchers ${ }^{23}$ who assert that it is crucial to strengthen the health system in different ways for perinatal care in DHs to be able to reduce neonatal mortality. However, this is not possible without understanding the broader organisational context, an issue that has been raised in implementation studies. ${ }^{24}$ Our study showed that even though the DH directors, clinic leaders and managers were involved in supporting implementation, the device was used less than anticipated. Acknowledgement of the crucial managerial role of the medical doctor in labour wards is important, and we believe this cadre should have been given a role with higher responsibility, such as a local project leader role, to strengthen the implementation. The role of a strong management team is crucial in any complex intervention, ${ }^{25} 26$ or as a basic component of a functioning health system. ${ }^{25} 27$ If medical local doctors working in the DH labour room would lead the implementation, they may be able to create a stronger 
involvement of key people, such as other obstetricians, anaesthesiologists, operation theatre nurses and laboratory personnel because of the local hospital hierarchy. The key people could then address actions needed to reduce delays, such as time from decision to delivery when indicated in cases of fetal distress. The model may motivate the local staff to find solutions, increases the feeling of ownership of the process and supports sustainable development. In addition, the introduction of a verbal audit system ${ }^{28}$ in the DH may motivate doctors. Joint meetings could also help doctors find solutions to local challenges such as preserving skills acquired after training in conducting instrumental deliveries, despite high physician turnover.

\section{Adequate resources}

One limitation to a FHRM implementation programme's sustainability could be lack of human resources in some DHs. Without an adequate staffing of labour wards to allow FHRM, the introduction of FHR recording by any means is not currently actually possible in these hospitals. A study from Uganda $2020^{29}$ came to the same conclusion about the shortage of staff. In Bihar, 'Mamtas', staff without a health-related education, assist staff nurses/ ANMs during labour and could be trained to use the device. However cultural norms need to be considered and reporting systems should be planned carefully. Human resources and division of work tasks need to be discussed at the DH management level.

\section{Device and training package feasibility}

The results indicate that the device in itself is easy to use. The usefulness of Moyo FHRM as a device compared with Doppler supported findings from previous studies such as the possibility to monitor several women in labour simultaneously and to be able to react faster to fetal distress because of the alarms. ${ }^{11}{ }^{12}$ This is important in DHs where the high workload is one of the biggest challenges when implementing FHRM. The user perspective is also important, and like in previous studies ${ }^{3031}$ the use of Moyo FHRM increased the perceived quality of the care provided.

Staff nurses/ANMs were positive to FHRM implementation and quick to learn how to use the Moyo. However, in order for doctors who make the final decisions on interventions, to act based on the Moyo FHRM findings, more extensive, focussed training appeared necessary, including training on operative vaginal delivery, which was lacking in the DHs. One of the obvious challenges is the decision-making process when the pathological FHR has been identified, including which action to take and how fast. As previous studies have shown, improved fetal surveillance is associated with reduction of labour time $^{32}$ due to the decision to expedite the delivery. Since many of the doctors working in DH's have not been able to use either Doppler or CTG regularly according to WHO's recommendations, ${ }^{7}$ the decision-making process may feel very challenging. Even though the Moyo FHRM allows continuous monitoring, and the 30-min histogram display button gives important additional information, without training material that compares the Moyo and CTG histograms in different scenarios, as well as instructive examples, the decision-making process tends to rely mainly on the alarms. When the Moyo alerts, there is little time left to act before it is too late and therefore an earlier oversight over the situation would be beneficial. Both development of training materials specifically for doctors, as well as offering existing online CTG training courses could be useful.

\section{Quantitative data and study design feasibility}

The quantitative data collection revealed several challenges. First, a substantial amount of data for the women included was missing. Second, it showed that restricting the inclusion of women to inclusion and exclusion criteria can be difficult. Third, our new variables may not have suited the context well enough and we may not have captured what we intended. We aimed to exclude women who were about to give birth on admission and for whom it was too late to introduce Moyo FHRM. Yet, $41 \%$ of the mothers included in the data collection had a fully dilated cervix on admission, indicating imminent birth. This could be one explanation for the low use of the Moyo FHRM during the post-implementation period, in addition to the lack of staff. We do not know how long they were in the labour ward from admission to birth. Another challenge was the categorisation of length of pregnancy. Moyo is designed for term pregnancies. In the four DHs staff and women define a pregnancy as term, preterm, very preterm and do not use gestational weeks of pregnancy on admission. Thus, the CAFs collected data of women considered eligible by staff, but found to be less than 37 weeks gestation when calculating from last menstrual period or Ultrasound scan, both of which can be uncertain in the given context. A quarter of the newborns weighed $2.5 \mathrm{~kg}$ or less and this could be an indication that women were included with a preterm pregnancy.

\section{Strengths}

A strength of this feasibility study is the use of both qualitative and quantitative methods. Combined their evidence contribute to understanding how complex interventions work and for whom, and how, in this case, health systems respond and adapt. ${ }^{33}$ Our study provides information for future implementation on the barriers and facilitators as well as the challenges concerning satisfactory data collection to assess the impact on obstetrical and neonatal outcomes. The study also considered social norms through early engagement with local staff in the DHs and using the existing health infrastructure as well as considering cultural and environmental influences.

\section{Limitations}

Some questions in the quantitative data questionnaire were not clear enough and could be misunderstood. 
Quantitative data collected was limited and does not give the whole picture of the situation. Since the number of quantitative data participants and the use of the Moyo devices was low, the study does not allow for reliable interpretation of the pre-implementation and postimplementation data due to insufficient power. Data collection does not give an answer of the women's attitudes and perceptions on using The Moyo FHRM during labour. ${ }^{34}$ The first author performing the interviews may have influenced the findings.

\section{CONCLUSION}

Our findings emphasise, in agreement with other studies ${ }^{35}$ the importance of careful intervention design and pre-implementation planning in response to the local health system and staff context in order to increase likelihood of effective and sustainable implementation. Health system challenges are a major constraint to the Moyo FHRM implementation in Bihar DHs. In the future, to be able to take Moyo FHRM in use, several areas need improvement. Pivotal are sufficient human resources in the labour ward. To ensure this, it is essential that the $\mathrm{DH}$ management and medical leadership not only see the need for FHRM during labour but initiate and own the process of implementation. In addition, improvements at all levels of infrastructure, practices and skills will be critical to strengthen operative FHRM in DHs to assure that a diagnosis of fetal distress during labour is adequately and timely responded to. User support during implementation should be continuous $24 / 7$ during the first weeks and frequent expert support ought to be available for several months after the initial implementation. To assess a future implementation, a full-scale mixed methods study should be performed. Routine quantitative data of high quality should be collected continuously (day and night, every day) for all eligible women, either permanently or at intervals. Appropriate data collection requires a clear strategy to communicate inclusion and exclusion criteria and preventing missing data as well as improved commonly agreed on variable and category definitions that allow accurate assessment of appropriate use of Moyo FHRM and obstetrical and neonatal outcomes.

\section{Author affiliations}

${ }^{1}$ Department of Obstetrics and Gynecology, South Norwegian Hospital SSHF, Kristiansand, Agder, Norway

${ }^{2}$ Faculty of Life Science and Education, University of South Wales, Pontypridd, Rhondda Cynon Taff, UK

${ }^{3}$ Solutions for Sustainable Development, CARE India, Patna, Bihar, India ${ }^{4}$ Paediatric Surgery, Madhipura Christian Hospital, Madhipura, Bihar, India

${ }^{5}$ Department of Nursing and Health Promotion, Oslo Metropolitan University, Oslo, Akershus, Norway

${ }^{6}$ Department of Obstetrics and Gynecology, Oslo University Hospital HF, Oslo, Norway

${ }^{7}$ Faculty of Health and Social Sciences, University of South-Eastern Norway, Kongsberg, Buskerud, Norway

Acknowledgements We would like to sincerely thank all the staff members and management teams in the four district hospitals, CARE Bihar clinical training experts who trained the local staff nurses/auxiliary nurse midwives in the participant district hospitals, as well as all the mothers giving birth and participating in the study.

Contributors HO, ML, AG, SM, SS, PN, SB and IS planned and designed the study. $\mathrm{HO}, \mathrm{SM}, \mathrm{AG}$ and SS carried out the data collection. KR and SS performed the quantitative data analysis and $\mathrm{HO}$ and $\mathrm{ML}$ qualitative data analysis. $\mathrm{HO}$ and $\mathrm{ML}$ discussed and interpreted the findings. HO drafted the paper. ML, KR, SM, AG, SS, $\mathrm{SB}$ and IS contributed to writing the manuscript. All the authors (HO, ML, KR, SM, AG, SS, PN, SB and IS) reviewed and approved the final manuscript.

Funding The feasibility study was supported by Laerdal Foundation. The Funding sponsor had no role in the design of the study, in the data collection, analyses or interpretation of data, in the writing of the manuscript or in the decision to publish the results.

Competing interests None declared.

Patient consent for publication Obtained.

Ethics approval The study followed the Helsinki Protocol (WMA Declaration of Helsinki at www.wma.net) and ethical approval was obtained from the Bihar Medical Health ethics committee as well as from the Norwegian Regional Committees for Medical Health Research Ethics South East. In the labour ward, participants were informed about the study and provided verbal consent written down by staff nurses. Routine clinical performance and patient information was recorded using confidential codes and these were kept in a safe and secure place by the investigators. All involved, management and staff, were informed of the collection of field notes, and clinical training experts consented to the interviews. All were reassured that data would be kept confidential and reporting would avoid the recognition of individuals.

Provenance and peer review Not commissioned; externally peer reviewed.

Data availability statement Data are available upon reasonable request. As an assessment of the feasibility of the implementation, this study was conducted in a close collaboration between the authors. The data sets generated and/or analysed during the current study are not publicly available, but are available from the corresponding author upon reasonable request.

Supplemental material This content has been supplied by the author(s). It has not been vetted by BMJ Publishing Group Limited (BMJ) and may not have been peer-reviewed. Any opinions or recommendations discussed are solely those of the author(s) and are not endorsed by BMJ. BMJ disclaims all liability and responsibility arising from any reliance placed on the content. Where the content includes any translated material, BMJ does not warrant the accuracy and reliability of the translations (including but not limited to local regulations, clinical guidelines, terminology, drug names and drug dosages), and is not responsible for any error and/or omissions arising from translation and adaptation or otherwise.

Open access This is an open access article distributed in accordance with the Creative Commons Attribution Non Commercial (CC BY-NC 4.0) license, which permits others to distribute, remix, adapt, build upon this work non-commercially, and license their derivative works on different terms, provided the original work is properly cited, appropriate credit is given, any changes made indicated, and the use is non-commercial. See: http://creativecommons.org/licenses/by-nc/4.0/.

ORCID iD

Hanna Oommen http://orcid.org/0000-0003-1810-9664

\section{REFERENCES}

1 WHO. Making Every Baby Count - Audit and review of stillbirths and neonatal deaths. Geneva, Switzerland: WHO Document Production Services, 2016.

2 Lawn JE, Blencowe H, Oza S, et al. Every newborn: progress, priorities, and potential beyond survival. The Lancet 2014;384:189-205.

3 Lawn JE, Bahl R, Bergstrom S, et al. Setting research priorities to reduce almost one million deaths from birth asphyxia by 2015. PLoS Med 2011;8:e1000389.

4 Lawn JE, Blencowe H, Kinney MV. Evidence to inform the future for maternal and newborn health. Best practice \& research. Clinical obstetrics \& gynaecology 2016;36:169-83.

5 WHO. Standards for improving quality of maternal and newborn care in health facilities. WHO Library, 2016.

6 Figo. Figo intrapartum fetal monitoring guidelines, 2017. Available: http://www.figo.org/news/available-view-figo-intrapartum-fetalmonitoring-guidelines-0015088 [Accessed 18 Sep 2019]. 
7 WHO. Who guidelines and recommendations. intrapartum care for a positive childbirth experience, 2018. Available: https://extranet.who. int/rhl/guidelines/who-recommendations-intrapartum-care-positivechildbirth-experience [Accessed 20 Jan 2020].

8 Bullens L. Management of fetal distress during term labor Eindhoven: Technische Universiteit Eindhove, 2018.

9 Hofmeyr GJ, Haws RA, Bergström S, et al. Obstetric care in lowresource settings: what, who, and how to overcome challenges to scale up? Int J Gynaecol Obstet 2009;107 Suppl 1:S21-45.

10 laerdalglobalhealth. Laerdal global health webpage. Available: https://laerdalglobalhealth.com/products/moyo-fetal-heart-ratemonitor/ [Accessed 13 Sep 2019]

11 Rivenes Lafontan S, Kidanto HL, Ersdal HL, et al. Perceptions and experiences of skilled birth attendants on using a newly developed strap-on electronic fetal heart rate monitor in Tanzania. BMC Pregnancy Childbirth 2019;19:165.

12 Kamala BA, Ersdal HL, Dalen I, et al. Implementation of a novel continuous fetal Doppler (Moyo) improves quality of intrapartum fetal heart rate monitoring in a resource-limited tertiary hospital in Tanzania: an observational study. PLoS One 2018;13:e0205698.

13 Ministry of Health and Family Welfare, Maternal Health Division. LaQshya standard operating procedures for DHs, 2018. Available: https://nhm.gov.in/New Updates 2018/NHM Components/ RMNCHA/MH/Guidelines/DH_SOP_LaQshya.pdf [Accessed 11 Feb 2020].

14 Bajpai V. The challenges confronting public hospitals in India, their origins, and possible solutions. Adv Public Health 2014;2014:1-27.

15 Muralidharan K, Chaudhury N, Hammer J. "Is There a Doctor in the House? Medical Worker Absence in India," Working paper. Department of Economics, Faculty of Arts and Sciences, Harvard University, 2011. Available: http://scholar.harvard.edu/files/kremer/ files/is_there_a_doctor_in_the_house_-_12_april_2011.pdf [Accessed 15 Jun 2019].

16 Organization WH. Global Health Observaroty (GHO) data - India. Available: http://www.who.int/gho/countries/ind/en/ [Accessed 2 Feb 2018].

17 IIfPSla ICF. National family health survey (HFHS-4) India 2015-16 Bihar. Mumbai: IPPS, 2017.

18 Care.org. Bihar technical support program. Available: https://www. care.org/work/health/sexual-and-reproductive-health-and-rights/ what-we-do/health-systems/bihar-technical [Accessed 20 May 2019].

19 Creswell JW, Clark VLP. Designing and conducting mixed methods research.. In: Analysing and interpreting data in mixed methods research. California: Sage publications, 2011: 203-50.

20 Census Organization of India. 15th national census survey. Available: http://www.census2011.co.in/states.php [Accessed 11 Feb 2020].

21 Msemo G, Massawe A, Mmbando D, et al. Newborn mortality and fresh stillbirth rates in Tanzania after helping babies breathe training. Pediatrics 2013;131:e353-60.

22 Hsieh H-F, Shannon SE. Three approaches to qualitative content analysis. Qual Health Res 2005;15:1277-88.
23 Horwood C, Haskins L, Phakathi S, et al. A health systems strengthening intervention to improve quality of care for sick and small newborn infants: results from an evaluation in district hospitals in KwaZulu-Natal, South Africa. BMC Pediatr 2019;19:29.

24 Greenhalgh T, Robert G, Macfarlane F, et al. Diffusion of innovations in service organizations: systematic review and recommendations. Milbank Q 2004;82:581-629.

25 Allanson ER, Tunçalp Özge, Vogel JP, et al. Implementation of effective practices in health facilities: a systematic review of cluster randomised trials. BMJ Glob Health 2017;2:e000266.

26 Aarons GA, Ehrhart MG, Farahnak LR, et al. Leadership and organizational change for implementation (loci): a randomized mixed method pilot study of a leadership and organization development intervention for evidence-based practice implementation. Implement Sci 2015;10:11.

27 World Health Organization. Monitoring the building blocks of health systems: a Handbook of indicators and their measurement strategies. Geneva: World Health Organization, 2010.

28 World Health Organization. Making every baby count: audit and review of stillbirths and neonatal deaths. highlights from the who 2016 audit guide. Available: https://apps.who.int/iris/bitstream/ handle/10665/250124/WHO-RHR-16.11-eng.pdf;jsessionid=BB81 F23196BAC5A6075AE9F11F8AF209? sequence $=1$ [Accessed 4 Jul 2020].

29 Ayebare E, Jonas W, Ndeezi G, et al. Fetal heart rate monitoring practices at a public hospital in Northern Uganda - what health workers document, do and say. Glob Health Action 2020;13:1711618.

30 Mdoe PF, Ersdal HL, Mduma E, et al. Randomized controlled trial of continuous Doppler versus intermittent fetoscope fetal heart rate monitoring in a low-resource setting. Int J Gynaecol Obstet 2018:143:344-50.

31 Rivenes Lafontan S, Sundby J, Kidanto HL, et al. Acquiring knowledge about the use of a newly developed electronic fetal heart rate monitor: a qualitative study among birth attendants in Tanzania. Int J Environ Res Public Health 2018;15:ijerph15122863. doi:10.3390/ijerph15122863

32 Maude RM, Skinner JP, Foureur MJ. Intelligent structured intermittent auscultation (IsiA): evaluation of a decision-making framework for fetal heart monitoring of low-risk women. BMC Pregnancy Childbirth 2014;14:184.

33 Noyes J, Booth A, Moore G, et al. Synthesising quantitative and qualitative evidence to inform guidelines on complex interventions: Clarifying the purposes, designs and outlining some methods. BMJ Glob Health 2019;4:e000893.

34 Rivenes Lafontan S, Sundby J, Ersdal HL. "I Was Relieved to Know That My Baby Was Safe": Women's Attitudes and Perceptions on Using a New Electronic Fetal Heart Rate Monitor during Labor in Tanzania. Int J Environ Res Public Health 2018.

35 Geerligs L, Rankin NM, Shepherd HL, et al. Hospital-Based interventions: a systematic review of staff-reported barriers and facilitators to implementation processes. Implement Sci 2018;13:36. 